\title{
Percutaneous placement of peritoneal dialysis catheters in resource-limited developing countries as an alternative to conventional placement methods
}

\author{
Authors: \\ Hendrik R. van den Berg \\ Suzanne O'Hagan² \\ Delme Hurter

\begin{abstract}
Affiliations:
${ }^{1}$ Registrar in Radiology, University of the Free State,

Bloemfontein, South Africa Kimberley Provincial

Hospital, South Africa

${ }^{3}$ Department of Radiology,

Kimberley Provincial
\end{abstract} \\ ${ }^{2}$ Medical Officer in Radiology, \\ Hospital, South Africa \\ Correspondence to: \\ Hendrik van den Berg \\ Email: \\ rynovandenberg@hotmail. \\ com \\ Postal address: \\ PO Box 11828, Universitas \\ 9321, South Africa \\ Dates: \\ Received: 03 Aug. 2014 \\ Accepted: 06 Feb. 2015 \\ Published: 29 Apr. 2015 \\ How to cite this article: \\ Van den Berg, H.R., \\ O'Hagan, S, Hurter, D. S \\ Afr J Rad. 2015;19(1); Art. \\ \#707, 8 pages. http://dx.doi. \\ org/10.4102/sajr.v19i1.707

\section{Copyright:} \\ C 2015. The Authors. \\ Licensee: AOSIS \\ OpenJournals. This \\ work is licensed under \\ the Creative Commons \\ Attribution License.
}

Read online:
Background: The percutaneous placement of peritoneal dialysis (PD) catheters using conscious sedation with ultrasound and fluoroscopic guidance is underutilised and has several advantages over the open surgical and laparoscopic placement methods, especially in the resource-limited developing world.

Objectives: To describe our patients' demographics and clinical characteristics, our method of PD catheter placement within the Radiology Department at Kimberley Provincial Hospital, compare our early complication types and frequencies, overall peritonitis rate and one-year catheter survival rate with findings in the international literature and, by demonstrating comparable outcomes, propose that percutaneous placement be considered as a feasible alternative to conventional placement techniques.

Method: We conducted a retrospective study on 25 patients who had their PD catheters inserted between January 2009 and May 2013. Medical records were reviewed for demographic and clinical information as well as type and frequency of early (within 30 days) and late (between 30 days and one-year) complications related to the PD catheter. Early complication types and frequencies were then compared with similar internationally published data. The overall peritonitis rate, in terms of episodes per patient-year, was calculated and compared with international recommendations, and our one-year catheter survival rate was calculated using the Kaplan Meier method and compared with similarly calculated international studies.

Results: The study group comprised 16 male and 9 female patients with a median age of 44 years. Hypertension was the primary cause of end-stage renal disease (ESRD), and was found in $10(40 \%)$ patients. Our early exit site infection rate of $12 \%$ was slightly higher than that found in the literature. Literature varies on the overall infection rates; however, our overall peritonitis rate of 0.75 episodes per patient-year was higher than that recommended by the International Society of Peritoneal Dialysis. This finding might be attributed to the lower socio-economic grouping of our patients and the small number in the study group. All but two peritonitis cases were successfully treated with antibiotics, and we had no major procedure-related complications. Our early peritonitis rate of $8 \%$, as well as the other early complication types and rates, and our one-year catheter survival rate of $84 \%$, compared favourably with international studies.

Conclusion: Percutaneous PD catheter placement under conscious sedation with the aid of ultrasound and fluoroscopy is a sound alternative to conventional methods in the resourcelimited developing world.

\section{Introduction}

End-stage renal disease (ESRD) is at least 3-4 times more common in Africa than in developed countries. ${ }^{1}$ In Africa, ESRD affects mainly adults aged 20 - 50 years, and predominantly results from hypertension and/or glomerular disease. In developed countries, ESRD occurs more commonly in the older age group, where it mainly stems from hypertension and/or diabetes. The burden of managing this condition places additional financial and economic pressure on an already impoverished continent. ${ }^{1}$

Renal transplantation as a treatment modality requires medical and surgical expertise, financial resources and a donor system. According to the South African Renal Registry Annual Report 2012, less than $20 \%$ of patients on renal replacement therapy for ESRD receive renal transplantation. This figure includes public and private sector patients. ${ }^{2}$ 
Renal dialysis is therefore the mainstay of ESRD treatment, but is underutilised, mainly owing to financial constraints. Two well-established methods of dialysis are haemodialysis (HD) and peritoneal dialysis (PD).

PD is a most effective renal replacement therapy that offers several advantages over HD.

These include:

- better patient mobility and quality of life

- more flexible scheduling

- encourages employment and independence

- ease of use

- lower cost if the dialysate fluid is produced locally

- preferable in certain comorbidities, such as cardiovascular disease, liver disease, diabetes and patients with electrolyte disturbances

- preservation of residual renal function

- lower mortality during the first year after initiating therapy. $3,4,5$

The advantages of PD make it a viable treatment option for ESRD in resource-limited developing countries where a chronic dialysis programme can be sustained.

The major disadvantages of PD compared with HD include:

- risk of infection, especially peritonitis

- the requirement for daily dialysis. In comparison, HD patients are usually dialysed three times per week.

- PD patients have less contact with medical personnel and other patients than HD patients

- PD patients need to store all of their dialysate fluid at home. ${ }^{3,4,5}$

The major disadvantages of HD include:

- need for vascular access, with infection risk

- more stringent diet, including strict fluid restrictions

- post dialysis physical symptoms, such as headache and lethargy.,3,5

PD catheters (Tenckhoff catheters) are usually placed using open surgical, laparoscopic and percutaneous (Seldinger) techniques.,4 Various international studies have been conducted comparing the techniques by assessing patient outcomes, costs and related complications of these different placement techniques.

Disadvantages of the laparoscopic and open surgical techniques, compared with the percutaneous method, are:

- the need for a willing and experienced surgeon

- operating room time

- need for general anaesthesia and associated expertise

- specialised equipment

- more invasive procedure

- longer hospital stay and higher costs

- waiting times for placement are longer, with the risk of interim patient deterioration. . $, 5,6,7^{-1}$
Advantages of the percutaneous method are:

- more expedient placement

- no need for specialised surgical skills

- no operating room time, as the procedure can be performed in the fluoroscopy suite

- bypassing the risks associated with general anaesthesia

- placement in patients unable to tolerate general anaesthesia

- faster recovery time

- less costly, with a shorter hospital stay

- similar or lower complication rates, depending on patient selection

- ultrasound and fluoroscopy facilities are available in most hospitals. $4,8,9,10,11$

We place PD catheters via the percutaneous method with the assistance of ultrasound and fluoroscopy under conscious sedation within the Radiology Department at Kimberley Provincial Hospital. This report describes our method and is a retrospective analysis of patient outcomes.

\section{Research method and design}

Approval was obtained from Kimberley Hospital's Clinical Manager and the Research and Ethics Committee of the University of the Free State. We retrospectively analysed the hospital records of 25 patients who had their PD catheters inserted between January 2009 and May 2013. These records are kept at the hospital's dialysis unit. We collected data using a pro forma, recording early (within the first 30 days) and late (>30 days up to 1 year) complications and their frequencies, patient demographics (age and gender), causes of renal failure, comorbidities and the referring physician's reasons for choosing this placement method.

The type and frequency of predetermined catheter-related complications were documented within the two time intervals mentioned above. We also noted whether the catheter was removed, how long after the insertion date it was removed, and the reason for removal.

Non-surviving patients were included. Patients were excluded if they defaulted their follow-up within the first year after placement or if their hospital records were incomplete or missing.

Outcome assessment was based on:

- Comparing our early catheter-related complication types and frequencies to those in similar international studies.

- Determining our one-year catheter survival rate (calculated as the percentage of normally functioning catheters after one-year from the insertion date, using the Kaplan Meier method) and comparing it with similarly calculated international studies.

- Determining our overall peritonitis rate (calculated as number of infections, divided by time at risk and expressed as episodes per patient-year) and comparing it with international recommendations. 
Data were analysed with the aid of the Biostatistics Department of the University of the Free State.

\section{Technique \\ Preoperative evaluation}

We excluded patients with previous abdominal or pelvic surgery, previous peritonitis, previous penetrating abdominal injury and abdominal hernia because of the risk of adhesions increasing the complication rate.

Patients were discussed with the radiologist prior to performing the procedure. Patients required an $\mathrm{Hb}>8 \mathrm{~g} / \mathrm{dl}$, with a normal clotting profile (INR $<1.4$ ).

Patients were kept nil per mouth from $22 \mathrm{~h} 00$ on the night preceding the procedure. The patients' abdomens were washed with Hibiscrub on the preceding day and the morning of the procedure. Bowel preparation was administered with two doses of Colo-prep the day before the procedure and patients were only allowed fluids orally. They were given Paracetamol $1 \mathrm{~g}$ orally two hours prior to the procedure for pain relief, and Vancomycin $1 \mathrm{~g}$ and Amikacin $500 \mathrm{mg}$ IV one hour prophylactically prior to the procedure.

\section{Procedure}

After confirming suitable blood results, excluding contraindications including allergies, the procedure was explained and the patient asked to empty their bladder before being taken into the fluoroscopy suite. Because the catheter was subcutaneously tunnelled from the infra-umbilical entrance site to the catheter exit site, the exit site was marked prior to starting the procedure. With the patient standing erect, the exit site is just lateral to the midclavicular line and just superior to the patient's belt line (Figure 1).

The patient then lay supine on the fluoroscopy table and a screening abdominal ultrasound was done to confirm

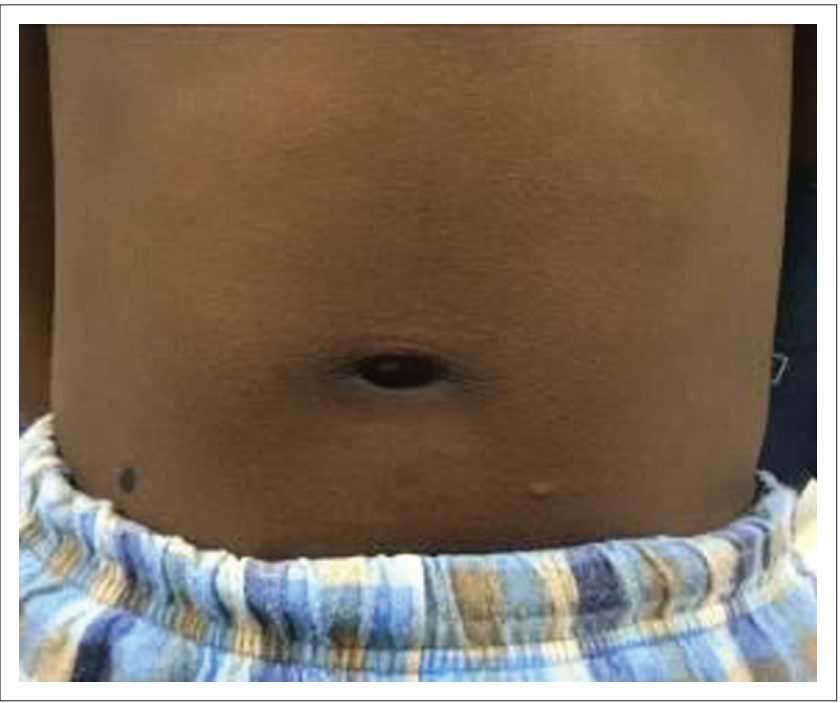

Source: The authors of this article: Van den Berg, H.R., O'Hagan, S, Hurter, D.

FIGURE 1: Marked catheter exit site is on the right, just lateral to the midclavicular line above the patient's belt line. an empty bladder and to check for any unsuspected intraabdominal pathology. Patient monitoring was set in place (pulse oximeter, ECG and blood pressure cuff) and intravenous access was obtained. An anaesthetist performed conscious sedation, according to own drug preference. The radiologist and assistant scrubbed up and cleaned the anterior abdominal wall, which was then draped using the standard sterile technique. The catheter insertion site was identified on the midline, just infra-umbilically, and infiltrated with $2 \%$ lignocaine without adrenaline (Figure 2).

A vertical incision of $2 \mathrm{~cm}-3 \mathrm{~cm}$ was made at the insertion site with blunt dissection through the subcutaneous tissue up to the rectus sheath. A $20 \mathrm{ml}$ syringe was filled with saline and directly connected to a 16-gauge IV needle/cannula assembly that was slowly advanced inferiorly through the rectus sheath, whilst the rectus sheath was lifted anteriorly using an artery forceps. Gentle pressure was simultaneously applied to the plunger until resistance was lost, confirming the intra-peritoneal position. The cannula was then advanced whilst the syringe and needle were removed (Figure 3).

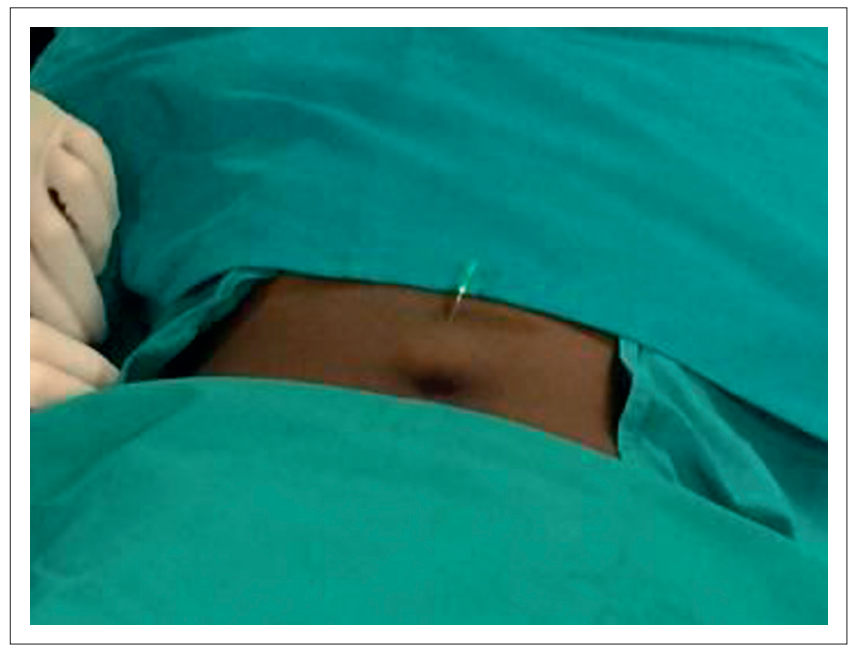

Source: The authors of this article: Van den Berg, H.R., O'Hagan, S, Hurter, D. FIGURE 2: The entrance site is within the midline, just infra-umbilically.

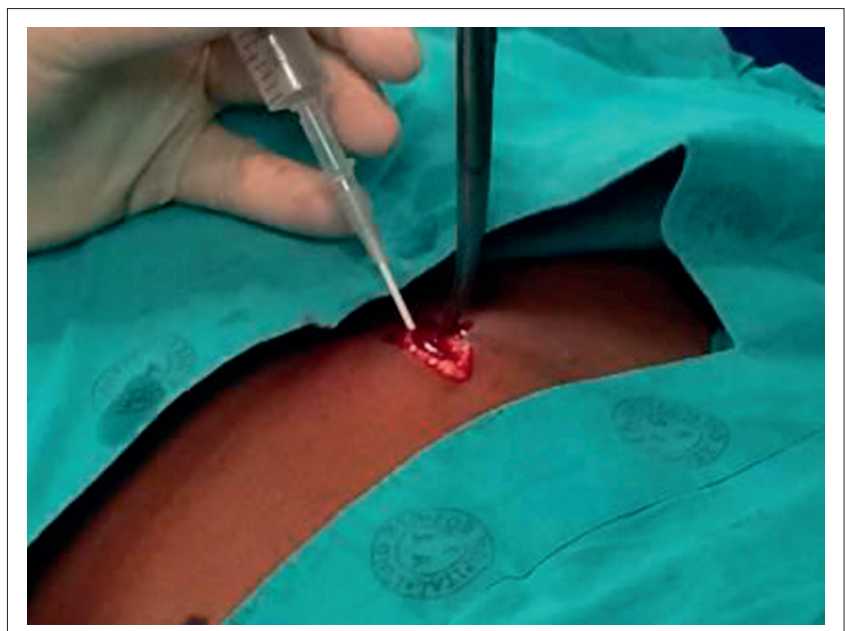

Source: The authors of this article: Van den Berg, H.R., O'Hagan, S, Hurter, D.

FIGURE 3: Syringe filled with saline attached to IV needle/cannula being advanced through the rectus sheath. 


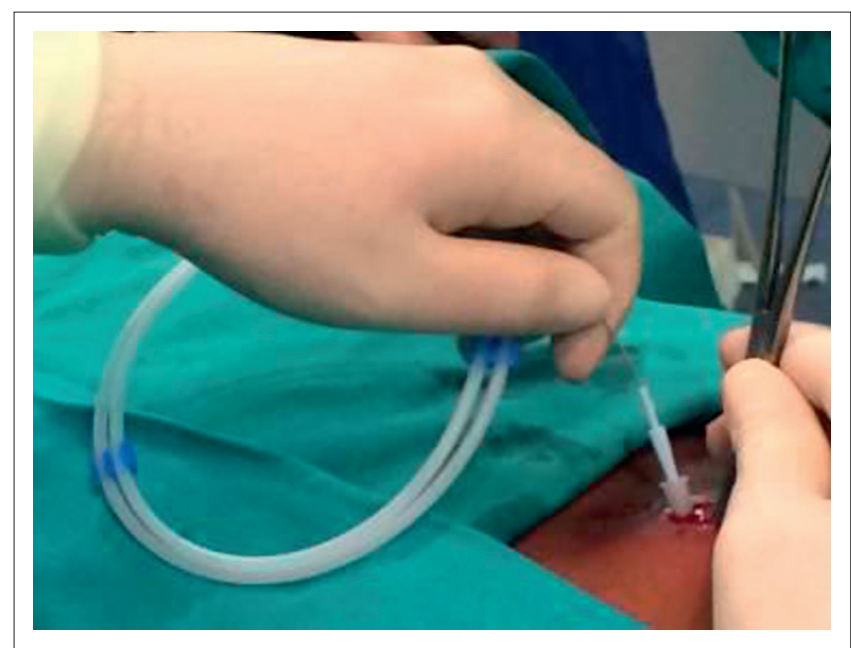

Source: The authors of this article: Van den Berg, H.R., O'Hagan, S, Hurter, D.

FIGURE 4: Guidewire being advanced through the cannula into the pelvis, whilst the rectus sheath is slightly lifted.

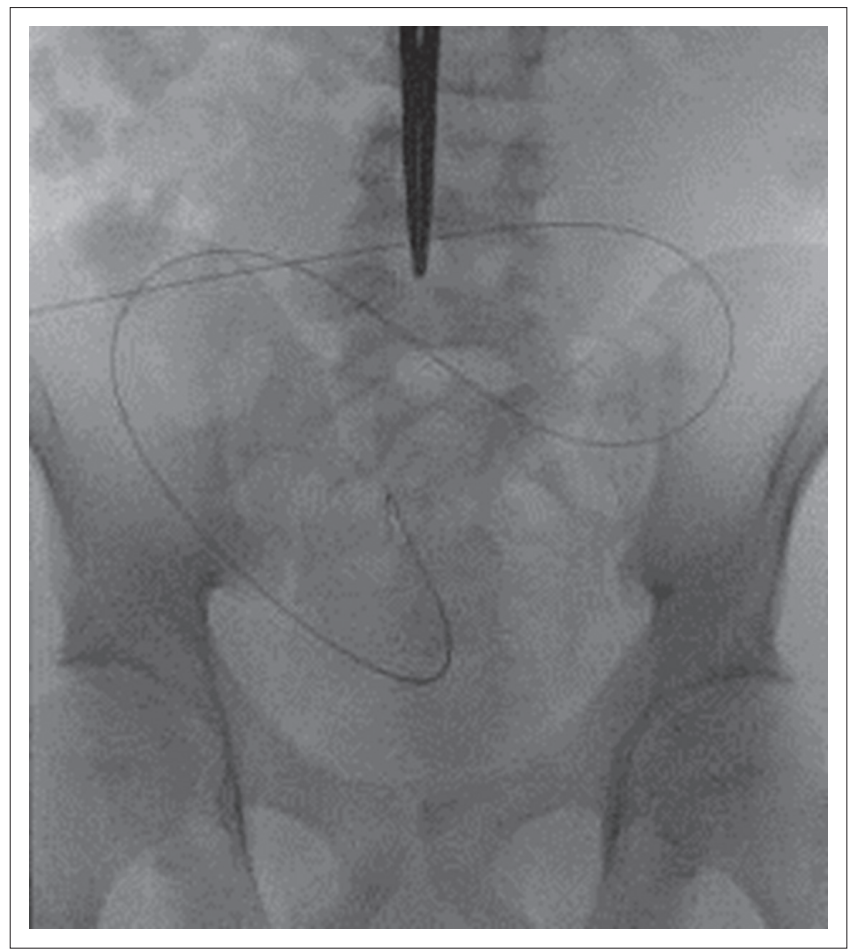

Source: The authors of this article: Van den Berg, H.R., O'Hagan, S, Hurter, D.

FIGURE 5: Correct position of the guidewire intra-peritoneally within the pelvis.

The rigid guidewire supplied with the kit (Medionics International, Ontario, Canada) was advanced through the cannula and directed towards the pelvis under fluoroscopic guidance (Figure 4 and Figure 5).

The cannula was removed and the entrance site was sequentially dilated over the guidewire with $10-16 \mathrm{~F}$ dilators, with the provided peel-away sheath covering the final $18 \mathrm{~F}$ dilator. The dilator tip position within the pelvis was confirmed fluoroscopically (Figure 6).

The dilator was removed and the $62 \mathrm{~cm}$ coiled, double-cuff PD catheter (Medionics International, Ontario, Canada)

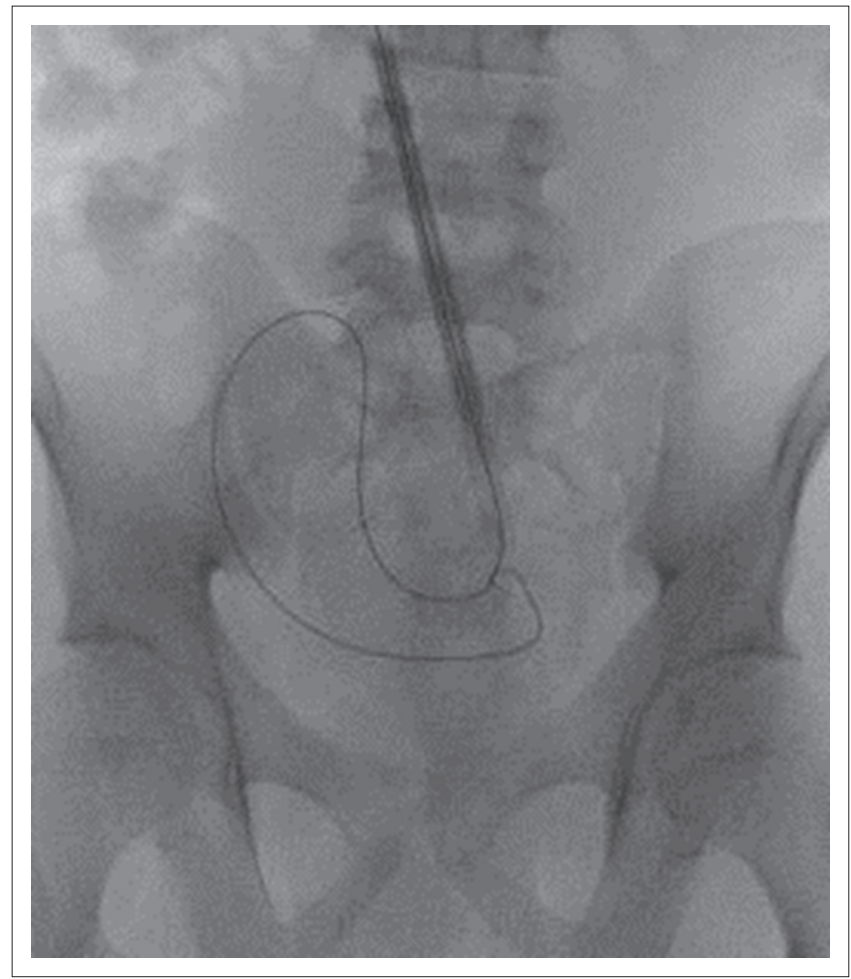

Source: The authors of this article: Van den Berg, H.R., O'Hagan, S, Hurter, D.

FIGURE 6: Final dilator and peel-away sheath, with guidewire positioned intra-peritoneally within the pelvis.

introduced over the guidewire and through the peel-away sheath into the peritoneal cavity with its coiled tip within the pelvis. The catheter's inner cuff was advanced up to the rectus sheath whilst the peel-away sheath was removed. The position within the pelvis was again confirmed fluoroscopically.

A $0.5 \mathrm{~cm}$ vertical incision was then made at the previously marked exit site and the catheter was tunnelled subcutaneously through the exit site, leaving the outer cuff buried within the subcutaneous tissue (Figure 7). It is important not to have any acute turns, twists or tension on the catheter.

Functionality was tested by infusing $500 \mathrm{ml}$ of PD fluid through the catheter. It should flow freely, without any pericatheter leaks. The fluid was then drained again and monitored for evidence of acute haemorrhage or bowel content. The bag was disconnected and replaced by the locking adaptor (Baxter Healthcare Corporation, Deerfield, USA) (Figure 8).

The entrance skin incision was approximated using the interrupted horizontal mattress suturing technique with Nylon $3 / 0$ and covered with a sterile dressing. The catheter exit site was covered with sterile gauze and an Opsite dressing specifically not applied to the catheter (to prevent difficulty in subsequent removal). The exit site was not sutured to avoid seroma and potential infection (Figure 9). 


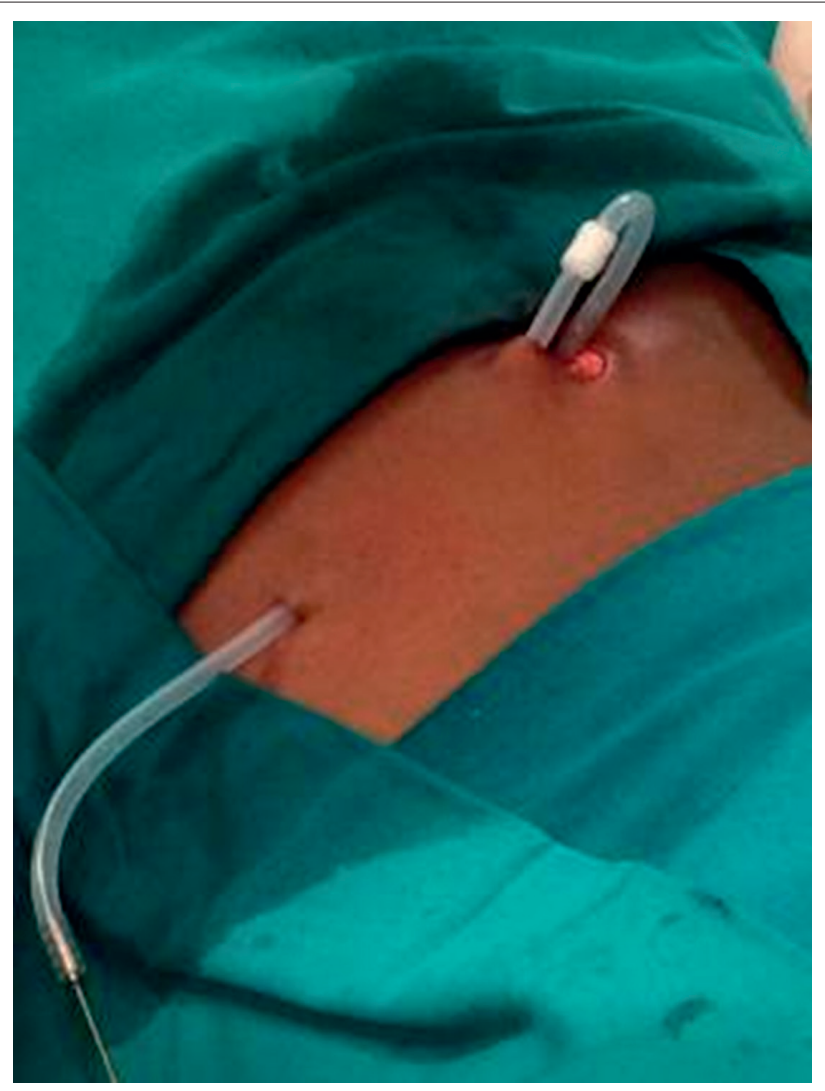

Source: The authors of this article: Van den Berg, H.R., O'Hagan, S, Hurter, D.

FIGURE 7: Peritoneal dialysis catheter tunnelled subcutaneously from the entrance site to the exit site.

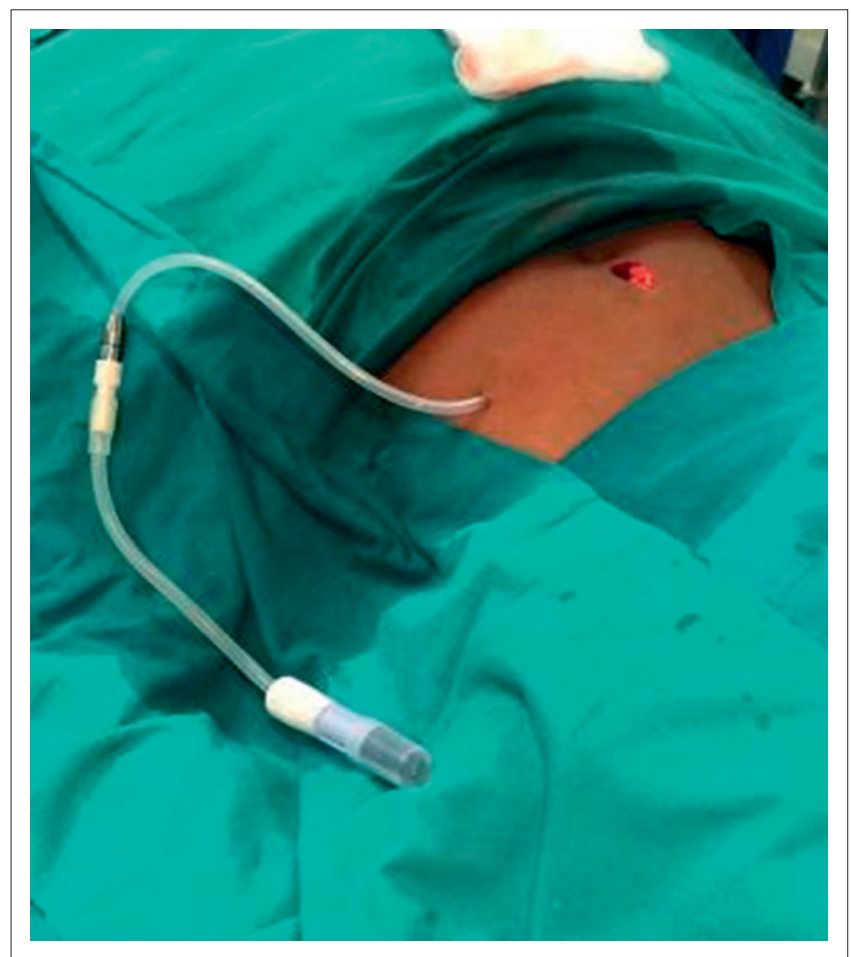

Source: The authors of this article: Van den Berg, H.R., O'Hagan, S, Hurter, D.

FIGURE 8: Peritoneal dialysis catheter with locking adaptor. Functionality was tested, and there was no evidence of acute complications.

A control pelvic radiograph was taken to document and confirm the correct position of the catheter (Figure 10).

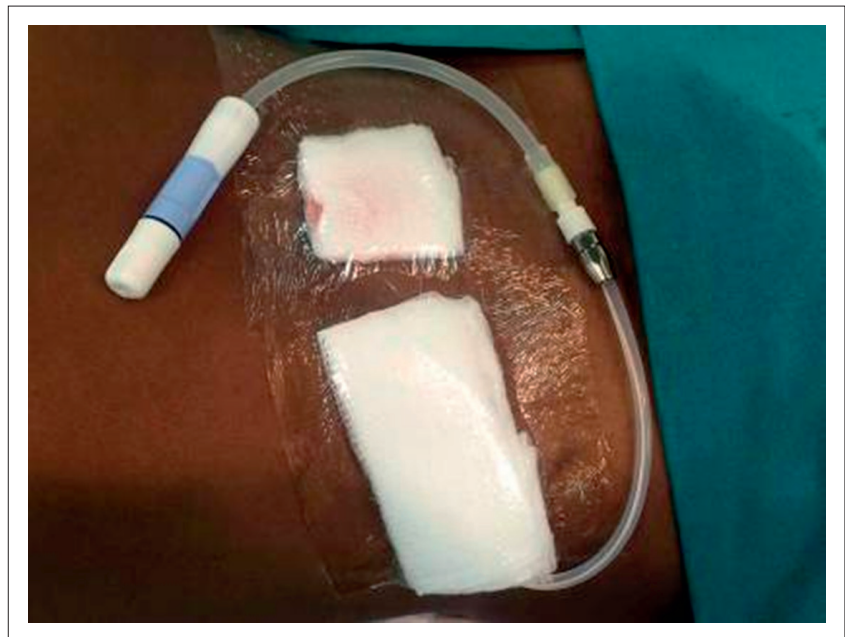

Source: The authors of this article: Van den Berg, H.R., O'Hagan, S, Hurter, D. FIGURE 9: Peritoneal dialysis catheter after being covered with dressings.

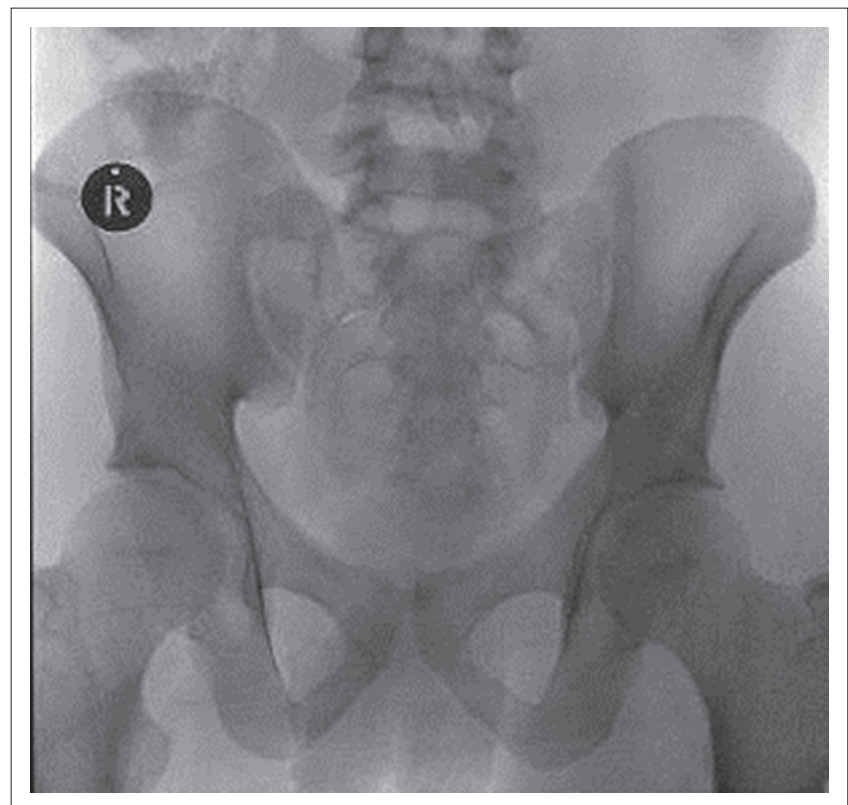

Source: The authors of this article: Van den Berg, H.R., O'Hagan, S, Hurter, D.

FIGURE 10: Control pelvic radiograph showing the peritoneal dialysis catheter correctly positioned within the pelvis.

\section{Results}

\section{Patient demographics and clinical characteristics}

Table 1 shows the demographic data and clinical characteristics of the group of 25 patients with 16 men (64\%) and nine women (36\%). Ages ranged from 18-60 years, with a median of 44 years.

Hypertension was the primary cause of ESRD in 10 patients $(40 \%)$, followed by diabetes mellitus in 5 patients $(20 \%)$. These data appear to be more in line with causes found in the developed world as opposed to literature stating hypertension and glomerular disease as being the main causes of ESRD in Africa. ${ }^{1}$ Nine patients $(36 \%)$ had two comorbidities and eight patients $(32 \%)$ had one comorbidity. Hypertension was present in 12 patients (48\%); cardiovascular disease was the next most prevalent comorbidity, found in 10 patients $(40 \%)$. 
TABLE 1: Patient demographics and clinical characteristics.

\begin{tabular}{lc}
\hline Variable & Number of patients (\%) \\
\hline Gender & $16(64)$ \\
Male & $9(36)$ \\
Female & \\
Cause of CRF & $10(40)$ \\
Hypertension & $5(20)$ \\
Diabetes mellitus & $3(12)$ \\
Glomerulonephritis & $2(8)$ \\
Analgesic nephropathy & $1(4)$ \\
Polycystic kidney disease & $4(16)$ \\
Unknown & \\
Comorbidities & $12(48)$ \\
Hypertension & $10(40)$ \\
Cardiovascular disease & $4(16)$ \\
Malnutrition & $3(12)$ \\
Secondary hyperparathyroidism & $1(4)$ \\
Obesity & $1(4)$ \\
Gout & $1(4)$ \\
HIV-positive & \\
Number of comorbidities per patient & $6(24)$ \\
0 & $8(32)$ \\
1 & $9(36)$ \\
2 & $2(8)$ \\
3 &
\end{tabular}

At our institution, all the patients were started on HD, because they needed urgent acute dialysis owing to their poor clinical condition and were selected for PD, based on patient preference, an acceptable social and psychological evaluation, and absence of contra-indications.

Our method of catheter insertion, as well as the open surgical technique under general anaesthesia in theatre by the general surgeon, were available options. There were two classes of reasons for choosing to insert the catheters percutaneously under conscious sedation within the Radiology Department, instead of under general anaesthesia in theatre. In 23 cases, this was because of lack of theatre time and/or unavailability of a surgeon, and in two cases because of the high risk of general anaesthesia. Our study confirms the utility of the percutaneous placement method as an alternative, especially with limited resources.

\section{Complications}

Table 2 shows catheter-related complications encountered within the first 30 days. Two patients had minor bleeding at the infra-umbilical entrance site immediately after catheter placement. The bleeding was controlled prior to the patient leaving the fluoroscopy room, one by manual compression and the other by cauterisation.

Of the three patients who developed acute exit site infection, one progressed to intractable peritonitis, and his catheter was removed after 10 days. This was also the only HIV-positive patient. A second patient who developed peritonitis was successfully treated with antibiotics.

Table 3 shows catheter-related complications encountered between 30 days and one year after catheter placement. One
TABLE 2: Complications within 30 days.

\begin{tabular}{lc}
\hline Type of complication & Number of patients (\%) \\
\hline Bowel or bladder perforation & 0 \\
Bleeding & $2(8)$ \\
Exit site infection & $3(12)$ \\
Outflow dysfunction & 0 \\
Exit site leakage & 0 \\
Catheter malposition & 0 \\
Peritonitis & $2(8)$ \\
Patient death & 0 \\
\hline $\begin{array}{l}\text { Exit site infection = Pericatheter erythema; Outflow dysfunction = Extra- or intra-luminal } \\
\text { obstruction; Exit site leakage = Pericatheter leakage of clear fluid; Catheter malposition } \\
\text { = Catheter not in pelvis; Peritonitis = Abdominal pain, cloudy fluid, fever, raised infective } \\
\text { markers or organism cultured on the fluid }\end{array}$
\end{tabular}

TABLE 3: Complications from $>30$ days -1 year.

\begin{tabular}{|c|c|}
\hline Type of complication & Number of patients $(\%)$ \\
\hline Exit site or tunnel infection & $1(4)$ \\
\hline Catheter extrusion & 0 \\
\hline Hernia & 0 \\
\hline Outflow dysfunction & $1(4)$ \\
\hline Exit site leakage & 0 \\
\hline Catheter malposition & $1(4)$ \\
\hline Peritonitis & $7(28)$ \\
\hline Death & 3 \\
\hline
\end{tabular}

patient's catheter migrated out of the pelvis and was removed after 47 days owing to irremediable outflow dysfunction. Another patient's catheter kinked and was removed after 33 days. A further patient developed exit site infection and seven patients developed peritonitis. Of these seven, the catheter was removed in only one case owing to intractable peritonitis; the remainder were treated successfully with antibiotics with no recurrent related infections during the one-year follow-up.

In total, nine patients developed peritonitis over the one-year follow-up period, which gave us an overall peritonitis rate of 0.75 episodes per patient-year.

The 3 patients who died before the one-year follow-up had normally functioning catheters at the time of death. Only four catheters were removed during the one-year follow-up period. Using the Kaplan Meier method, this gave a one-year catheter survival rate of $84 \%$.

\section{Discussion}

Table 4 shows the comparisons in early complication rates between our study and similar internationally published studies. We had two cases $(8 \%)$ of minor intra-operative bleeding at the infra-umbilical entrance site. Maya described his technique using ultrasound guidance to gain access into the peritoneal cavity and colour Doppler flow to identify and avoid vasculature. He reported no bleeding complications in his 32-patient study population. ${ }^{12}$

Our early exit site infection rate of $12 \%$ is slightly higher than that found in the literature, which ranges from 
TABLE 4: Comparison of our early complications with similar published studies.

\begin{tabular}{|c|c|c|c|c|c|c|}
\hline Study & Our study & Maya $^{12}$ & Vaux $^{13}$ & Savader $^{10}$ & Zaman $^{14}$ & Jacobs $^{15}$ \\
\hline Number of successfully placed catheters & $25 / 25$ & $32 / 32$ & $200 / 209$ & $19 / 19$ & $34 / 36$ & $45 / 45$ \\
\hline \multicolumn{7}{|l|}{ Complications } \\
\hline Bladder perforation & 0 & 0 & 0 & 0 & 0 & 0 \\
\hline Bowel perforation & 0 & $1 / 32(3 \%)$ & 0 & 0 & 0 & $2 / 45(4.4 \%)$ \\
\hline Pericatheter leaks & 0 & 0 & $10 / 200(5 \%)$ & 0 & $1 / 34(2.9 \%)$ & $3 / 45(6.6 \%)$ \\
\hline Exit-site infections & $3 / 25(12 \%)$ & 0 & $13 / 200(6.5 \%)$ & 0 & 0 & $N R$ \\
\hline Peritonitis & $2 / 25(8 \%)$ & 0 & $3 / 200(1.5 \%)$ & $1 / 19(5.2 \%)$ & $2 / 36(5.5 \%)$ & $7 / 45(15 \%)$ \\
\hline Catheter dysfunction & 0 & $1 / 32(3 \%)$ & $14 / 200(7 \%)$ & 0 & $1 / 34(2.9 \%)$ & $9 / 45(20 \%)$ \\
\hline Bleeding & $2 / 25(8 \%)$ & 0 & $\mathrm{NR}$ & NR & $1 / 34(2.9 \%)$ & $3 / 45(6.6 \%)$ \\
\hline
\end{tabular}

NR, not recorded.

$0-8.2 \% \cdot{ }^{9,10,11,12,13,14,15}$ The increased infection rate might be attributable to the lower socio-economic status of the patient population or the small study group.

Our early peritonitis rate of $8 \%$ is comparable to that cited, which ranges from $0-15 \% .{ }^{9}, 10,11,12,13,14,15$

Our patients had no bowel or bladder perforations, pericatheter leaks or early catheter dysfunction, comparing favourably with other studies, where these events ranged from $0-4.4 \%, 0-6.6 \%$ and $0-20 \%$ respectively. ${ }^{9,10,11,12,13,14,15}$

The overall quoted infection rates vary; our peritonitis rate of 0.75 episodes per patient-year is, however, higher than that recommended by the International Society of Peritoneal Dialysis 2010 update. They recommend aiming for less than 0.67 episodes per patient-year. This difference could be related to our patient's socio-economic circumstances. ${ }^{16}$ However, of our nine peritonitis cases, all but two patients were successfully treated with antibiotics, and we had no recurrent episodes within the one-year follow-up period.

Our one-year catheter survival rate of $84 \%$ is comparable to the findings of Vaux et al., Savader et al. and Zaman et al. who recorded one-year catheter survival rates of $77 \%, 81 \%$ and $89 \%$, respectively. ${ }^{10,13,14}$

\section{Limitations of the study}

The study was retrospectively performed, with relatively small patient numbers. Certain patients were excluded from the procedure in the preoperative evaluation, but some who were unfit for general anaesthesia were included.

\section{Conclusion}

There is good evidence that percutaneous placement of PD catheters under conscious sedation has advantages over the open surgical and laparoscopic placement techniques. The procedure is relatively easy and can be performed in any hospital with ultrasound and fluoroscopy facilities. There were no major complications in our series and, except for a slightly elevated infection rate, outcomes were on a par with comparable international data regarding complications and catheter survival. Percutaneous PD catheter placement under conscious sedation with the aid of ultrasound and fluoroscopy is therefore a sound alternative to conventional methods in the resource-limited developing world.

\section{Acknowledgements Competing interests}

The authors declare that they have no financial or personal relationship(s) that may have inappropriately influenced them in writing this article.

\section{Authors' contributions}

H.R.v.d.B. (University of the Free State), was project leader, wrote the study protocol, obtained ethical approval, collected data, analysed the data and wrote the article. S.O'H. (Kimberley Hospital), collected data, reviewed and gave input on the final article. D.H. (Kimberley Hospital), was the supervisor and gave input on the final article.

\section{References}

1. Naicker, S. End-stage renal disease in sub-Saharan Africa. Ethn Dis. 2009; 9 13-15.

2. Davids MR, Marais N, Jacobs, JC. South African Renal Registry Annual Report 2012 South African Renal Society 2014. c2014 [cited 25 October 2014]. Available from: http://sa-renalsociety.org

3. Ellsworth PI, Kim ED. Peritoneal dialysis catheter insertion. Medscape, September 2012. c2012 [cited 01 January 2013]. Available from: http://emedicine.medscape. com/article/1829737overview

4. Yip T, Lui SL, Lo WK. Review article: The choice of peritoneal dialysis catheter implantation technique by nephrologists. International Journal of Nephrology. 2013; article ID 940106. http://dx.doi.org/10.1155/2013/940106

5. Peppelenbosch A, van Kuijk WHM, Bouvy ND, van der Sande FM, Tordoir JHM Peritoneal dialysis catheter placement technique and complications. NDT Plus. 2008;1 (Suppl 4):iv23-iv28. http://dx.doi.org/10.1093/ndtplus/sfn120

6. Brunier G, Hiller JA, Drayton S, Pugash RA, Tobe SW. A change to radiological peritoneal dialysis catheter insertion: Three-month outcomes. Peritoneal Dialysis International. 2010; 30:528-533. http://dx.doi.org/10.3747/pdi.2009.00114

7. Mellotte GJ, Ho CA, Morgan SH, Bending MR, Eisinger AJ. Peritoneal dialysis catheters: A comparison between percutaneous and conventional surgical placement techniques. Nephrol Dial Transplant. 1993;8:626-630.

8. Voss D, Hawkins S, Poole G, Marshall M. Radiological versus surgical implantation of first catheter for peritoneal dialysis: A randomized non-inferiority trail. Nephro Dial Transplant. 2012; 27:4196-4204. http://dx.doi.org/10.1093/ndt/gfs305

9. Reddy C, Dybbro PE, Guest S. Fluoroscopically guided percutaneous peritoneal dialysis catheter placement: Single centre experience and review of literature. Renal Failure. 2010; 2:294-299. http://dx.doi. org/10.3109/08860220903548932

10. Savader SJ, Geschwind JF, Lund GB, Scheel PJ. Percutaneous radiological placement of peritoneal dialysis catheters: Long-term results. J Vasc Interv Radiol. 2000 1:965-970. http://dx.doi.org/10.1016/S1051-0443(07)61323-2

11. Georgiades CS, Geschwind JF. Percutaneous peritoneal dialysis catheter placement for the management of end-stage renal disease: Technique and comparison with the surgical approach. Techn Vasc Interv Radiol. 2002; 5:103-107. http://dx.doi. org/10.1053/tvir.2002.36054

12. Maya ID. Ultrasound/fluoroscopy-assisted placement of peritoneal dialysis catheters. Semin Dial. 2007;20:611-615. http://dx.doi.org/10.1111/j.1525-139X 2007.00371.x 
13. Vaux E, Torrie P, Barker L, Naik R, Gibson M. Percutaneous fluoroscopically guided placement of peritoneal dialysis catheters -10 year experience. Semin Dial. 2008;21:459-465. http://dx.doi.org/10.1111/j.1525-139X.2008.00463.x

14. Zaman F, Pervez A, Atray N, Murphy S, Work J, Abreo K. Fluoroscopy-assisted placement of peritoneal dialysis catheters by nephrologists. Semin Dial. 2005;18:247-251. http://dx.doi.org/10.1111/j.1525-139X.2005.18321.x
15. Jacobs IG, Gray RR, Elliott DS, Grosman H. Radiolologic placement of peritoneal dialysis catheters: Preliminary experience. Radiology 1992;182:251-255. $\mathrm{http}: / / \mathrm{dx}$.doi.org/10.1148/radiology.182.1.1727292

16. Li PKT, Szeto CC, Piraino B, et al. Peritoneal dialysis-related infections recommendations: 2010 Update. Perit Dial Int. 2010;30:393-423. http://dx.doi. org/10.3747/pdi.2010.00049 